\title{
Produção de soja e germinação carpogênica de Sclerotinia sclerotiorum sob diferentes coberturas de solo
}

\section{Soybean production and carpogenic germination of Sclerotinia sclerotiorum under different cover crops}

\author{
Luciano dos Reis Venturoso ${ }^{1 *}$; Lilian Maria Arruda Bacchi²; \\ Walber Luiz Gavassoni ${ }^{3}$; Lenita Aparecida Conus Venturoso ${ }^{1}$; \\ Daniel Luan Pereira Espindola'; João Aparecido Eugênio dos Santos ${ }^{4}$
}

\section{Resumo}

O trabalho teve por objetivo avaliar a influência de diferentes coberturas vegetais de solo sobre a germinação carpogênica de Sclerotinia sclerotiorum e sobre o desenvolvimento e rendimento da cultura da soja. Os tratamentos constaram da palhada de braquiária, canola, cártamo, crambe, girassol e nabo forrageiro, mais um controle sem cobertura. As culturas de cobertura foram semeadas em vasos contendo $4,4 \mathrm{dm}^{3}$ de solo do tipo Latossolo Vermelho Distroférrico. Após 45 dias o material vegetal foi cortado em pedaços de modo a padronizar a quantidade de palha para $2800 \mathrm{~kg} \mathrm{ha}^{-1}$. Posteriormente, sementes de soja foram semeadas e sete dias após a emergência das plântulas foram alocados dois escleródios de $S$. sclerotiorum por vaso. Em relação à germinação carpogênica, foi analisado o tempo para a germinação dos escleródios e formação dos apotécios, número de estipes e apotécios por escleródio e a porcentagem de apotécios formados. Na cultura da soja foi determinada a altura de plantas no florescimento e na colheita, índice relativo de clorofila, massa seca da parte aérea e de raiz, número de vagens por planta, número de sementes por vagem, rendimento, número de nódulos por planta e a massa seca de nódulos. Com exceção ao cártamo, constatou-se que o uso de cobertura vegetal do solo reduziu a formação de estipes e apotécios de S. sclerotiorum. As coberturas com braquiária, girassol e nabo forrageiro aumentaram em 16, 10 e 6 dias respectivamente o período para a formação do apotécio, porém, somente braquiária reduziu a porcentagem de apotécios formados. A cobertura do solo com palha de girassol prejudicou o desenvolvimento e o rendimento da cultura da soja.

Palavras-chave: Glycine max, coberturas vegetais, germinação de escleródios

\begin{abstract}
The aim of this work was to evaluate the influence of different soil cover crops on the carpogenic germination of Sclerotinia sclerotiorum and the development and yield of soybean. The treatments consisted of mulches of brachiaria, canola, safflower, crambe, sunflower and forage radish mulch, and a control with no cover mulch. The crops were sown in pots containing $4.4 \mathrm{dm}^{3}$ of soil type Rhodic Acrustox. After 45 days the plant material was cut into pieces in order to standardize the amount of straw to $2800 \mathrm{~kg} \mathrm{ha}^{-1}$. Soybean seeds were sown and seven days after seedling emergence two sclerotia were allocated in each pot. With regard to carpogenic germination, we analyzed the time to germination of sclerotia and formation of apothecia, number of stipes and apothecia per sclerotia and the percentage

\footnotetext{
${ }^{1}$ Eng $^{{ }_{s}}$ Agr $^{\text {ss }}$, Discente(s) de Doutorado do Programa de Pós-Graduação em Agronomia, Universidade Federal da Grande Dourados, UFGD, Dourados, MS. E-mail: luck_rv@hotmail.com; lenitaconus@yahoo.com.br

${ }^{2}$ Eng $^{\mathrm{a}}$ Agr ${ }^{\mathrm{a}}$, Prof ${ }^{\mathrm{a}}$. Dr ${ }^{\mathrm{a}}$. da Faculdade de Ciências Agrárias, FCA, UFGD, Dourados, MS. E-mail: lilianbacchi@ufgd.edu.br

${ }^{3}$ Eng $^{\text {o Agro }}$, Prof. Ph.D. da Faculdade de Ciências Agrárias, FCA, UFGD, Dourados, MS. E-mail: walber.gavassoni@ufgd.edu.br

${ }^{4}$ Discente(s) de Agronomia, UFGD, Dourados, MS. E-mail: danielluanblz@hotmail.com; jaeds200@hotmail.com

* Autor para correspondência
} 
apothecia formed. In the soybean crop was determined plant height at flowering and harvest, relative chlorophyll index, dry matter mass and root, number of pods per plant, number of seeds per pod, grain yield, number of nodules per plant and dry mass of nodules. With the exception of safflower mulch, the use of cover crops reduced the formation of stipes and apothecia of $S$. sclerotiorum. The covers with brachiaria, sunflower and forage radish mulch increased by 16, 10 and 6 days respectively the overall period of apothecium formation, but only brachiaria reduced the percentage of apothecia formed. The sunflower mulch hindered soybean development and yield.

Key words: Glycine max, vegetal mulch or cover crops, sclerotia germination

\section{Introdução}

A soja está consolidada como uma das principais culturas do agronegócio brasileiro. Esse patamar foi alcançado tanto pelo aumento da área cultivada, como, principalmente, pelo expressivo incremento em sua produtividade. Todavia, a expansão da cultura aliada à falta de cuidados fitossanitários possibilitou aumento na disseminação de patógenos em todas as áreas cultivadas. Entre as doenças que incidem sobre a soja, o mofo branco, causado pelo fungo Sclerotinia sclerotiorum (Lib) de Bary, tem se destacado como uma das mais importantes, principalmente em regiões de clima temperado.

$\mathrm{Na}$ cultura da soja, a fase mais vulnerável ao patógeno estende-se da floração plena ao início da formação de vagens e enchimento dos grãos (DANIELSON; NELSON; HELMS, 2004). O fungo é capaz de infectar qualquer parte da planta, porém, as infecções iniciam-se com mais frequência a partir das inflorescências, das axilas das folhas e dos ramos laterais (ALMEIDA et al., 1997). Em condições de clima favorável, como alta umidade e temperaturas amenas, o patógeno pode ocasionar danos severos, resultando em grandes perdas de rendimento (WRATHER et al., 1997).

Sclerotinia sclerotiorum é um patógeno de distribuição mundial e apresenta ampla gama de hospedeiros, podendo atacar mais de 400 espécies (BOLTON; THOMMA; NELSON, 2006). O fungo sobrevive no solo, conservando seu poder patogênico por vários anos, por meio de estruturas de resistência chamadas de escleródios. No solo, os escleródios podem germinar tanto de forma miceliogênica, considerada por Napoleão et al.
(2005) de potencial epidêmico reduzido, como carpogênica, com formação de apotécios. Nos apotécios são produzidos os ascósporos, principal fonte de inóculo do patógeno (SUN; YANG, 2000). Cada apotécio pode produzir de 2 a 30 milhões de ascósporos durante um período de até 10 dias (CLARKSON et al., 2003).

Como não há cultivares resistentes ao mofo branco, recomenda-se adotar medidas integradas, visando reduzir a população de estruturas de resistência do patógeno no solo e a formação de um ambiente desfavorável ao desenvolvimento da doença (LOBO JUNIOR et al., 2009). A cobertura do solo pode funcionar como barreira física, reduzindo a entrada de luz necessária à formação dos apotécios (GÖRGEN et al., 2009; PAULA JÚNIOR et al., 2009) e consequentemente a liberação de ascósporos, bem como barreira química, liberando compostos com capacidade de inibir completamente o crescimento do patógeno (PEDRAS; AHIAHONU; HOSSAIN, 2004).

O uso de cobertura vegetal no solo possibilita a melhoria da conservação do solo e da matéria orgânica e constitui considerável reserva de nutrientes (CRUSCIOL et al., 2005), que ao se decompor, altera os atributos químicos do solo e, como consequência, influencia a produtividade das culturas em sucessão (MARCELO et al., 2009). A manutenção dos resíduos na superfície ainda traz como benefício, a redução da magnitude das oscilações diárias da temperatura do solo e da evaporação e aumenta a conservação da umidade (GASPARIM et al., 2005), podendo aumentar a população das bactérias fixadoras de nitrogênio (CASTRO et al., 1993) e garantir condições 
adequadas para o estabelecimento de microorganismos que podem atuar como parasitas de fitopatógenos (GÖRGEN et al., 2009). Entretanto, os resíduos de muitas espécies podem interferir no estabelecimento e desenvolvimento de outras culturas, como é o caso do milho cultivado sobre palha de girassol (RONCATTO; VIECELLI, 2009).

A viabilidade do sistema de semeadura direta é dependente da utilização de coberturas vegetais capazes de amenizar problemas fitossanitários, favorecer a ciclagem de nutrientes e promover o equilíbrio dos atributos químicos, físicos e biológicos do solo. Diante do exposto objetivou-se avaliar a influência de diferentes coberturas de solo sobre a germinação carpogênica de $S$. sclerotiorum e sobre o desenvolvimento e rendimento da cultura da soja em sucessão.

\section{Material e Métodos}

Escleródios de S. sclerotiorum coletados em lavouras de soja foram transferidos para placas de Petri, em meio BDA, e incubados em câmara BOD a $20^{\circ} \mathrm{C} \pm 2^{\circ} \mathrm{C}$ e fotoperíodo de 12 horas. Após a formação da colônia fúngica, discos de micélio do patógeno foram transferidos para erlenmeyer contendo discos de cenoura previamente autoclavados a $120^{\circ} \mathrm{C}$ por vinte minutos e incubados novamente na mesma temperatura, porém, em escuro contínuo, para produção dos escleródios.

Foram testadas como cobertura vegetal do solo, plantas de braquiária (Brachiaria decumbens), canola (Brassica napus var. oleifera), cártamo (Carthamus tinctorius), crambe (Crambe abyssinica), girassol (Helianthus annus) e nabo forrageiro (Raphanus sativus), e uma testemunha com solo descoberto. Adotou-se o delineamento experimental inteiramente casualizado com 8 repetições.

As plantas de cobertura do solo foram cultivadas em casa de vegetação, com temperatura de $25^{\circ} \mathrm{C}$ $\pm 4^{\circ} \mathrm{C}$, enquanto as plantas de soja, da emergência ao estádio fenológico R3, permaneceram em sala climatizada, com temperatura de $23^{\circ} \mathrm{C}$ e umidade de $55 \%$, sendo posteriormente levadas para casa de vegetação.

O resultado da análise química do solo (Latossolo Vermelho Distroférrico) demonstrou valores de: $\mathrm{pH}$ em água 4,5, $1 \mathrm{mg} \mathrm{dm}^{-3} \mathrm{de} \mathrm{P}, 0,04$ $\mathrm{cmol}_{\mathrm{c}} \mathrm{dm}^{-3}$ de K, 0,3 $\mathrm{cmol}_{\mathrm{c}} \mathrm{dm}^{-3}$ de $\mathrm{Ca}, 0,2 \mathrm{cmol}_{\mathrm{c}}$ $\mathrm{dm}^{-3}$ de $\mathrm{Mg}, 1,04 \mathrm{cmol}_{\mathrm{c}} \mathrm{dm}^{-3}$ de $\mathrm{Al}$ e $5,5 \mathrm{cmol}_{\mathrm{c}} \mathrm{dm}^{-3}$ de $\mathrm{H}+\mathrm{Al}$. Conforme a análise química do solo, procedeu-se a calagem utilizando $1,67 \mathrm{~g} \mathrm{dm}^{-3} \mathrm{de}$ calcário dolomítico, visando obter uma saturação por bases de $60 \%$. As culturas de cobertura foram semeadas em vasos plásticos, contendo $4,4 \mathrm{dm}^{3}$ de solo fertilizado com $0,34 \mathrm{~g} \mathrm{dm}^{-3}$ de $\mathrm{P}_{2} \mathrm{O}_{5}, 0,09$ $\mathrm{g} \mathrm{dm}^{-3}$ de $\mathrm{K}_{2} \mathrm{O}$ e $0,04 \mathrm{~g} \mathrm{dm}^{-3}$ de N. Sete dias após a emergência, procedeu-se o desbaste das plântulas, deixando-se cinco por vaso.

Decorridos 45 dias de cultivo, realizou-se a coleta da parte aérea das plantas. O material vegetal foi cortado em pedaços, padronizando-se a quantidade de palha de $2800 \mathrm{~kg} \mathrm{ha}^{-1}$. Este valor foi obtido com base na cultura que apresentou menor produção de resíduos vegetais. A quantidade padronizada foi fracionada em fragmentos em torno de $4 \mathrm{~cm}$ de comprimento que foram espalhados homogeneamente sobre a superfície do solo. Posteriormente, foram semeadas dez sementes de soja, cultivar BRS 245, inoculadas com Bradyrhizobium japonicum. A adubação de base da soja foi realizada com $0,17 \mathrm{~g} \mathrm{dm}^{-3}$ de $\mathrm{P}_{2} \mathrm{O}_{5}, 0,07 \mathrm{~g}$ $\mathrm{dm}^{-3}$ de $\mathrm{K}_{2} \mathrm{O}$ e $0,1 \mathrm{mg} \mathrm{dm}^{-3}$ de Mo, e em cobertura, 50 dias depois, foram adicionados $0,03 \mathrm{~g} \mathrm{dm}^{-3} \mathrm{de}$ $\mathrm{K}_{2} \mathrm{O}, 2,0 \mathrm{mg} \mathrm{dm}^{-3}$ de $\mathrm{Zn}, 1,8 \mathrm{mg} \mathrm{dm}^{-3}$ de $\mathrm{Mn}, 0,8 \mathrm{mg}$ $\mathrm{dm}^{-3}$ de Fe, 0,7 mg dm ${ }^{-3}$ de $\mathrm{Cu}, 0,4 \mathrm{mg} \mathrm{dm}^{-3}$ de B e $0,1 \mathrm{mg} \mathrm{dm}^{-3}$ de Mo. Sete dias após a emergência, procedeu-se o desbaste das plântulas, deixando-se duas por vaso. No mesmo dia, foram alocados dois escleródios por vaso à aproximadamente $1 \mathrm{~cm}$ de profundidade.

Tanto para as culturas de coberturas como para a soja, a irrigação foi realizada a cada dois dias, 
pesando-se individualmente os vasos, de modo a manter a umidade do solo em $60 \%$ da capacidade de campo.

As sub-amostras das coberturas vegetais coletadas após seu corte e os trifólios de plantas de soja coletados no florescimento foram acondicionados em sacos de papel e secados em estufa com circulação forçada de ar a $55^{\circ} \mathrm{C}$ até atingirem massa constante. A seguir, os materiais foram moídos em moinho tipo Wiley e submetidos à análise química para determinação dos teores de nitrogênio, fósforo, potássio, cálcio e magnésio, conforme Malavolta, Vitti e Oliveira (1997).

Em relação à germinação carpogênica, analisouse o tempo para a germinação dos escleródios (TG) e para a formação dos apotécios (TFA), o número de estipes (NE) e apotécios (NA) por escleródio e a porcentagem de apotécios formados (PA) em relação ao número de estipes. Os escleródios foram considerados germinados quando pelo menos um estipe foi observado, sendo a coleta a partir de então, realizada a cada dois dias.

Durante o desenvolvimento da cultura da soja foi determinada a altura de plantas no florescimento (APF) e por ocasião da colheita (APC) (medindose do colo ao ápice das plantas) e o índice relativo de clorofila (IRC) no florescimento determinado de forma não destrutiva com clorofilômetro Minolta modelo SPAD-502 (Soil Plant Analysis Development). $\mathrm{Na}$ colheita foi quantificado o número de vagens por planta (NVP), o número de sementes por vagem (NSV) e o rendimento contabilizando-se o resultado em g.planta ${ }^{-1}$ com $13 \%$ de umidade. Também foi determinada a massa seca de raiz (MSR), o número de nódulos (NNOD) por planta e a massa seca de nódulos (MSN), após desagregação do solo contendo as raízes das plantas com peneira (malha de 2,5 mm). Para quantificar a massa seca da parte aérea (MSPA), MSR e a MSN, o material foi levado para estufa com circulação forçada de ar a uma temperatura de $55^{\circ} \mathrm{C}$ até a obtenção de massa constante.

Os dados foram submetidos a análise de variância com auxílio do programa SISVAR, e as médias comparadas pelo teste de agrupamento de Scott-Knott a $5 \%$ de probabilidade.

\section{Resultados e Discussão}

A análise estatística dos dados indicou efeito das coberturas com braquiária e girassol, as quais atrasaram a germinação carpogênica dos escleródios (TG) em relação aos demais tratamentos (Tabela 1). Possivelmente a palha de braquiária atuou como barreira física à germinação dos escleródios, fato que pode ser atribuído a maior persistência desta cobertura sobre a superfície do solo, reduzindo a luminosidade sobre os escleródios. A maior relação $\mathrm{C} / \mathrm{N}$ da palha de braquiária torna a decomposição dos resíduos lenta, proporcionando, de acordo com Görgen et al. (2009), cobertura eficiente e duradoura sobre o solo. Por outro lado, o girassol tem relação C/N baixa (SODRÉ FILHO et al., 2004), e a estrutura de seus resíduos foi constituída principalmente de hastes, fatores que impossibilitaram uma adequada cobertura do solo. Ainda assim, ocorreu um retardo na germinação dos escleródios, pressupondo a existência de compostos secundários produzidos durante a decomposição dos restos culturais do girassol, que podem ter afetado a germinação do patógeno. 
Tabela 1. Período total, em dias, (PT) para a ocorrência da germinação carpogênica dos escleródios (TG) e para a formação dos apotécios (TFA) de Sclerotinia sclerotiorum em soja cultivada com diferentes coberturas vegetais de solo.

\begin{tabular}{cccc}
\hline Culturas & TG (dias) & TFA (dias) & PT (dias) \\
\hline Braquiária & $65,5 \mathrm{a}$ & $16,2 \mathrm{a}$ & $81,7 \mathrm{a}$ \\
Canola & $56,7 \mathrm{~b}$ & $6,0 \mathrm{~b}$ & $62,7 \mathrm{~b}$ \\
Cártamo & $54,0 \mathrm{~b}$ & $10,2 \mathrm{~b}$ & $64,2 \mathrm{~b}$ \\
Crambe & $55,6 \mathrm{~b}$ & $8,2 \mathrm{~b}$ & $63,8 \mathrm{~b}$ \\
Girassol & $68,9 \mathrm{a}$ & $6,9 \mathrm{~b}$ & $75,8 \mathrm{a}$ \\
Nabo forrageiro & $58,4 \mathrm{~b}$ & $13,2 \mathrm{a}$ & $71,6 \mathrm{a}$ \\
Solo sem cobertura (SC) & $55,9 \mathrm{~b}$ & $8,3 \mathrm{~b}$ & $64,2 \mathrm{~b}$ \\
\hline CV (\%) & 5,32 & 18,30 & 5,58 \\
\hline
\end{tabular}

Médias seguidas pela mesma letra na coluna não diferem entre si pelo teste de agrupamento de Scott-Knott a 5\% de probabilidade. Fonte: Elaboração dos autores.

Constatou-se que o TFA foi prolongado nas coberturas com nabo forrageiro e braquiária, provocado provavelmente, pela maior permanência dos resíduos vegetais na superfície do solo. A palha de nabo não apresentou a mesma persistência que aquela verificada com o uso da braquiária, porém, foi superior às demais culturas estudadas. Para Ferraz et al. (1999), quanto maior a espessura da cobertura morta, maior será a dificuldade dos estipes chegarem à superfície e formarem os apotécios.

Observando-se o tempo transcorrido entre a colocação dos escleródios no solo até a formação dos apotécios (PT), destacam-se os resultados obtidos com a cobertura de braquiária, girassol e nabo forrageiro. Notou-se que, no solo sem cobertura (solo SC) e nas coberturas com canola, crambe e cártamo, o PT ocorreu próximo ao florescimento da soja, que em média, foi 65 dias após a semeadura. Considerando que a fase mais vulnerável da soja começa na floração plena (DANIELSON; NELSON; HELMS, 2004) e que as infecções iniciam-se a partir das inflorescências (ALMEIDA et al., 1997), práticas de manejo que retardem a formação dos apotécios, tornam-se ainda mais relevantes. As coberturas com braquiária, girassol e nabo forrageiro, atrasaram em torno de 16, 10 e 6 dias, respectivamente, a completa formação dos apotécios em relação a data de florescimento pleno da soja.
Observou-se maior NE e NA no solo SC e na palhada de cártamo (Figura 1A). As coberturas com canola, crambe, girassol, nabo forrageiro e braquiária, proporcionaram valores semelhantes de NE, enquanto que o NA por escleródio foi significativamente menor com o uso de braquiária, seguido de nabo forrageiro e girassol, e crambe e canola. Em estudo comparando a germinação de escleródios na presença e ausência de Brachiaria ruziziensis, Görgen et al. (2009) também verificaram redução no número de apotécios formados pela utilização da cobertura vegetal. Para Lobo Junior et al. (2009) a redução do número de apotécios formados sobre o solo, devido à camada de palha, é o efeito mais notável e imediato capaz de reduzir a severidade do mofo branco.

A presença da cobertura vegetal não impediu a formação de apotécios, porém, houve redução em seu número, em torno de 89,0, 59,2, 56,1, 41,0 e 35,7\% com as coberturas de braquiária, nabo forrageiro, girassol, crambe e canola, respectivamente. Estimase que um apotécio descarrega simultaneamente, 10.000 a 30.000 ascósporos maduros, e que pode produzir em um período de até dez dias, de 2 a 30 milhões de ascósporos (CLARKSON et al., 2003). Esses dados permitem inferir que, com exceção da cobertura com cártamo, a produção de inóculo para as safras subsequentes seria menor onde foi utilizada cobertura vegetal. Levando-se em consideração 
que o mofo branco é uma doença monocíclica, a redução do inóculo inicial, produzirá efeitos epidemiológicos benéficos para o desenvolvimento da cultura.

Figura 1. Número de estipes (NE) e de apotécios formados por escleródio (NA) "A" e porcentagem de apotécios formados (PA) em relação ao número de estipes germinados "B" em soja cultivada com diferentes coberturas vegetais de solo. Médias seguidas pela mesma letra na linha não diferem entre si pelo teste de agrupamento de Scott-Knott a $5 \%$ de probabilidade.

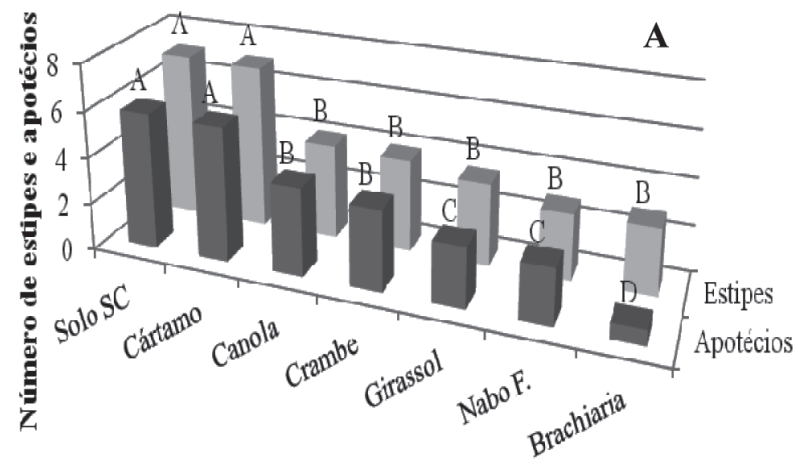

Coberturas

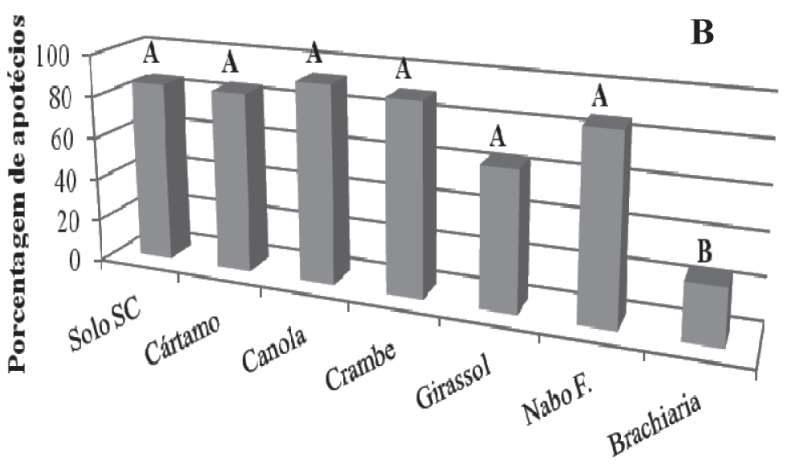

Coberturas

Fonte: Elaboração dos autores.

Os resultados deste estudo indicaram quepalhadas de culturas como canola, crambe, girassol e nabo forrageiro, espécies relatadas como hospedeiras de S. sclerotiorum, apresentaram redução sobre o NE e NA por escleródio do patógeno. O efeito antagonista dos micro-organismos presentes nas coberturas (SCHILLINGER; PAULITZ, 2006), ou ainda, a presença de compostos liberados durante a decomposição da palha podem ter inibido o desenvolvimento do patógeno. Angus et al. (1994), em estudos in vitro, demonstraram que compostos provenientes da decomposição de canola suprimiram o crescimento de Gaeumannomyces graminis var. tritici.

$\mathrm{Na}$ presença da cobertura com braquiária, apenas $26,2 \%$ dos estipes germinados se diferenciaram em apotécios, sendo significativamente inferior aos demais tratamentos (Figura 1B). A maior espessura da palha sobre o solo, além de proporcionar a formação de estipes longos e finos, limitou a luminosidade necessária para a diferenciação dos estipes em apotécios.
Vale salientar que mesmo atrasando a germinação dos escleródios e reduzindo o número de estipes e apotécios, o uso de cobertura vegetal não elimina a possibilidade de ocorrência da doença, todavia, poderá reduzir a severidade da mesma.

Observa-se na Tabela 2, que as coberturas influenciaram a APF, APC, MSPA, MSR, IRC e NNOD. De modo geral, essas características sofreram efeito do cultivo de cobertura anterior, constatando-se que a soja após o girassol apresentou menor APF, APC e IRC. Roncatto e Viecelli (2009) verificaram efeito similar quando o girassol foi utilizado como adubo verde e, independentemente da quantidade de resíduos, afetou o crescimento das plantas de milho.

Correia e Durigan (2006), em dois anos de cultivo, observaram maior acúmulo de matéria seca e altura de plantas de soja cultivada sobre cobertura de braquiária. No estudo, o efeito da palha de braquiária não se mostrou constante sobre a matéria seca total da soja, pois em relação à MSPA, as coberturas com girassol e braquiária 
resultaram nos menores valores, entretanto, a braquiária proporcionou maior MSR, seguida das coberturas com nabo forrageiro, canola e crambe. Bordin et al. (2008) não verificaram diferença no acúmulo de matéria seca de raízes de soja ou milho quando cultivados nos sistemas de plantio direto e convencional. No entanto, Silva e Rosolem (2002), salientam a importância da presença dos canais no solo, deixados por raízes do cultivo anterior.

Tabela 2. Altura de plantas no florescimento (APF), na colheita (APC), massa seca da parte aérea (MSPA), de raízes (MSR), índice relativo de clorofila (IRC) e número de nódulos (NNOD) por planta de soja cultivada com diferentes coberturas vegetais de solo.

\begin{tabular}{ccccccc}
\hline Coberturas & APF $(\mathrm{cm})$ & APC $(\mathrm{cm})$ & MSPA $(\mathrm{g})$ & MSR $(\mathrm{g})$ & IRC $(\mathrm{spad})$ & NNOD $\left(\mathrm{n}^{\circ}\right)$ \\
\hline Braquiária & $65,4 \mathrm{~b}$ & $74,4 \mathrm{a}$ & $2,01 \mathrm{~b}$ & $2,76 \mathrm{a}$ & $33,7 \mathrm{a}$ & $254,4 \mathrm{a}$ \\
Canola & $72,7 \mathrm{a}$ & $78,9 \mathrm{a}$ & $2,29 \mathrm{a}$ & $1,58 \mathrm{~b}$ & $32,5 \mathrm{a}$ & $274,8 \mathrm{a}$ \\
Cártamo & $66,8 \mathrm{~b}$ & $69,7 \mathrm{a}$ & $2,21 \mathrm{a}$ & $1,05 \mathrm{c}$ & $33,8 \mathrm{a}$ & $204,9 \mathrm{~b}$ \\
Crambe & $65,5 \mathrm{~b}$ & $76,4 \mathrm{a}$ & $2,49 \mathrm{a}$ & $1,47 \mathrm{~b}$ & $33,8 \mathrm{a}$ & $215,7 \mathrm{~b}$ \\
Girassol & $45,7 \mathrm{c}$ & $51,3 \mathrm{~b}$ & $1,61 \mathrm{~b}$ & $1,08 \mathrm{c}$ & $29,7 \mathrm{~b}$ & $176,2 \mathrm{~b}$ \\
Nabo forrageiro & $65,6 \mathrm{~b}$ & $76,3 \mathrm{a}$ & $2,37 \mathrm{a}$ & $1,71 \mathrm{~b}$ & $34,8 \mathrm{a}$ & $268,6 \mathrm{a}$ \\
Solo sem cobertura & $64,7 \mathrm{~b}$ & $73,8 \mathrm{a}$ & $2,60 \mathrm{a}$ & $1,28 \mathrm{c}$ & $32,5 \mathrm{a}$ & $205,0 \mathrm{~b}$ \\
\hline CV $(\%)$ & 4,81 & 7,79 & 8,06 & 7,48 & 3,91 & 11,28 \\
\hline
\end{tabular}

Médias seguidas pela mesma letra na coluna não diferem entre si pelo teste de agrupamento de Scott-Knott a 5\% de probabilidade. Fonte: Elaboração dos autores.

A maior quantidade de nódulos foi observada em soja cultivada sobre palha de canola, nabo forrageiro e braquiária. Maior nodulação e peso total de nódulos por planta, em sistema plantio direto, foram relatados por Castro et al. (1993), avaliando a atividade de micro-organismos em diferentes sistemas de manejo do solo. A proteção conferida com o uso da cobertura vegetal proporciona maior umidade e redução da oscilação térmica no solo, favorecendo o incremento no número de nódulos.

O aumento da nodulação em soja cultivada sobre cobertura vegetal também pode estar relacionado ao maior teor de matéria orgânica e fósforo no solo (CASTRO et al., 1993). Novo et al. (1999) estudando o efeito do potássio sobre a fixação biológica verificaram, com a cultivar de soja IAC-8, aumento na massa seca e no número de nódulos com a adição de 30,4 e $27,9 \mathrm{~kg} \mathrm{ha}^{-1}$ de $\mathrm{K}_{2} \mathrm{O}$, respectivamente. Entretanto, no estudo não foi observada correlação significativa entre os nutrientes presentes na palha das coberturas e o número de nódulos nas plantas de soja.
Os menores valores observados nos caracteres fisiológicos da cultura da soja sobre palha de girassol foram determinantes para que essa cobertura também proporcionasse NVP e rendimento de grãos inferiores aos demais tratamentos (Tabela 3). O número de vagens e o rendimento da soja, não foram influenciados quando o cultivo foi realizado em sucessão a diferentes adubos verdes, seja no sistema plantio direto ou convencional (CARVALHO et al., 2004). Görgen et al. (2009) relataram maior número de vagens em plantas submetidas ao tratamento com palha de $B$. ruziziensis, no entanto, o rendimento foi inferior quando comparado ao solo sem cobertura vegetal. Os autores atribuíram este fato a menor população de plantas na presença da braquiária.

Comparado ao tratamento sem cobertura do solo, nota-se incremento da ordem de 5,1, 7,5, 11,4 e $12,7 \%$ no rendimento da soja, quando cultivada sobre cobertura de braquiária, canola, nabo forrageiro e crambe, respectivamente, sem, contudo, apresentar diferença significativa. Confer, Buntin e Phillips (2006) relataram incremento no 
rendimento do trigo, quando cultivado em rotação com canola, porém após dois anos a produtividade foi semelhante ao cultivo do trigo em monocultura. Maiores produtividades da soja foram encontradas por Marcelo et al. (2009), quando realizada em sucessão a crotalária e nabo forrageiro. Os autores atribuíram o fato, aos elevados níveis de fósforo encontrado após o cultivo das culturas de cobertura.

Tabela 3. Número de vagens por planta (NVP), número de sementes por vagem (NSV) e rendimento de grãos de plantas de soja cultivadas com diferentes coberturas vegetais de solo.

\begin{tabular}{cccc}
\hline Coberturas & $\mathrm{NVP}\left(\mathrm{n}^{\mathrm{o}}\right)$ & $\mathrm{NSV}^{\mathrm{ns}}\left(\mathrm{n}^{\mathrm{o}}\right)$ & Rendimento $\left(\mathrm{g} \mathrm{planta}^{-1}\right)$ \\
\hline Braquiária & $30,6 \mathrm{a}$ & 1,47 & $7,45 \mathrm{a}$ \\
Canola & $30,3 \mathrm{a}$ & 1,49 & $7,62 \mathrm{a}$ \\
Cártamo & $25,8 \mathrm{a}$ & 1,49 & $6,19 \mathrm{a}$ \\
Crambe & $32,3 \mathrm{a}$ & 1,44 & $7,99 \mathrm{a}$ \\
Girassol & $18,1 \mathrm{~b}$ & 1,49 & $4,58 \mathrm{~b}$ \\
Nabo forrageiro & $30,9 \mathrm{a}$ & 1,49 & $7,90 \mathrm{a}$ \\
Solo sem cobertura & $29,1 \mathrm{a}$ & 1,43 & $7,09 \mathrm{a}$ \\
\hline $\mathrm{CV}(\%)$ & 12,80 & 1,61 & 10,70 \\
\hline
\end{tabular}

Médias seguidas pela mesma letra na coluna não diferem entre si pelo teste de agrupamento de Scott-Knott a 5\% de probabilidade. ns: não significativo.

Fonte: Elaboração dos autores.

A ausência de aumento significativo no rendimento da soja cultivada sobre cobertura vegetal pode ser atribuída à forma de irrigação realizada no trabalho, mantendo $60 \%$ da capacidade de campo, pois se observou que a quantidade necessária para manter este valor no tratamento sem cobertura do solo foi sempre superior aos demais tratamentos, principalmente até o início do florescimento. Pereira, Moreira e Klar (2002) relataram redução na frequência de irrigação, a partir de $50 \%$ de cobertura vegetal do solo. Os autores verificaram ainda, que o tratamento com $100 \%$ de cobertura propiciou economia de água de $29 \%$, quando comparado ao tratamento sem cobertura. Desta forma, o benefício em relação à manutenção da umidade do solo promovido pelas coberturas vegetais, não foi expresso devido à irrigação realizada neste ensaio.

Observou-se que o cultivo da soja sobre palha de girassol proporcionou redução de quase todos os parâmetros analisados, quando comparado ao tratamento sem cobertura do solo. Constatou-se, além de clorose nas folhas de soja, redução de 29,4, $30,5,38,1,15,6,8,6,14,1,37,8$ e $35,4 \%$ naAPF, APC,
MSPA, MSR, IRC, NNOD, NVP e rendimento de grãos, respectivamente, quando comparado com o solo sem cobertura. $\mathrm{O}$ efeito prejudicial às plantas de soja pode estar relacionado à presença de compostos alelopáticos presentes na palha de girassol. Entre as substâncias alelopáticas produzidas pelo girassol, estão os fenóis, terpenos (KUPIDLOWSKA et al., 2006) e flavonóides (CORSATO et al., 2010). A cultura tem apresentado efeitos inibitórios sobre a germinação e crescimento, tanto de invasoras como de plantas cultivadas (RONCATTO; VIECELLI, 2009; CORSATO et al., 2010).

As espécies vegetais utilizadas como cobertura do solo apresentaram teores diferentes de fósforo, potássio, cálcio e magnésio na matéria seca (Tabela 4). Foi encontrada maior concentração de potássio na palha de cártamo, que, ao lado do nabo forrageiro, também apresentou os maiores teores de cálcio. A maior quantidade de magnésio foi observada na cobertura com girassol. Em relação ao fósforo, destaca-se a cobertura com canola, que apresentou 2,58 $\mathrm{g} \mathrm{kg}^{-1}$ de palha, sendo superior aos demais tratamentos. 
Tabela 4. Teores de nutrientes presentes nas plantas utilizadas como cobertura vegetal e nas folhas da cultura da soja coletadas no florescimento.

\begin{tabular}{cccccc}
\hline \multirow{2}{*}{ Coberturas } & \multicolumn{5}{c}{ Teor de nutrientes nas plantas de cobertura $\left(\mathrm{g} \mathrm{kg}^{-1}\right)$} \\
\cline { 2 - 5 } & Nitrogênio $^{\text {ns }}$ & Fósforo & Potássio & Cálcio & Magnésio \\
\hline Braquiária & 11,2 & $0,80 \mathrm{f}$ & $23,00 \mathrm{~b}$ & $1,93 \mathrm{c}$ & $2,88 \mathrm{c}$ \\
Canola & 10,5 & $2,85 \mathrm{a}$ & $20,50 \mathrm{~b}$ & $10,09 \mathrm{~b}$ & $2,99 \mathrm{c}$ \\
Cártamo & 16,1 & $1,45 \mathrm{~d}$ & $31,25 \mathrm{a}$ & $14,37 \mathrm{a}$ & $3,55 \mathrm{~b}$ \\
Crambe & 13,3 & $2,07 \mathrm{c}$ & $21,75 \mathrm{~b}$ & $9,61 \mathrm{~b}$ & $1,83 \mathrm{~d}$ \\
Girassol & 10,5 & $0,96 \mathrm{e}$ & $21,50 \mathrm{~b}$ & $10,94 \mathrm{~b}$ & $4,00 \mathrm{a}$ \\
Nabo forrageiro & 9,8 & $2,59 \mathrm{~b}$ & $23,25 \mathrm{~b}$ & $15,20 \mathrm{a}$ & $3,55 \mathrm{~b}$ \\
\hline CV (\%) & 8,34 & 2,87 & 3,19 & 7,17 & 2,23 \\
\hline Coberturas & & Teor de nutrientes nas folhas de soja $\left(\mathrm{g} \mathrm{kg}^{-1}\right)$ & \\
& Nitrogênio & Fósforo & Potássions & Cálcion $^{\text {ns }}$ & Magnésions \\
\hline Braquiária & 46,9 & $3,69 \mathrm{a}$ & 27,00 & 15,46 & 4,81 \\
Canola & 46,2 & $3,33 \mathrm{c}$ & 22,75 & 16,10 & 4,61 \\
Cártamo & 45,5 & $3,70 \mathrm{a}$ & 30,00 & 14,91 & 4,42 \\
Crambe & 39,9 & $3,62 \mathrm{a}$ & 25,00 & 16,03 & 4,53 \\
Girassol & 44,1 & $3,28 \mathrm{c}$ & 25,25 & 14,92 & 4,65 \\
Nabo forrageiro & 46,9 & $3,49 \mathrm{~b}$ & 23,75 & 16,86 & 4,71 \\
Solo sem cobertura & 46,2 & $3,76 \mathrm{a}$ & 23,50 & 14,57 & 4,78 \\
\hline CV (\%) & 6,69 & 1,67 & 8,69 & 8,52 & 4,46 \\
\hline
\end{tabular}

Médias seguidas pela mesma letra na coluna não diferem entre si pelo teste de agrupamento de Scott-Knott a 5\% de probabilidade. ns: não significativo.

Fonte: Elaboração dos autores.

Salienta-se que apesar da diferença encontrada na composição nutricional das coberturas vegetais, não foi verificada diferença significativa na análise foliar da cultura da soja para nitrogênio, potássio, cálcio e magnésio. Apenas o conteúdo de fósforo foi influenciado pelas coberturas do solo, sendo constatado maior conteúdo do nutriente no tecido foliar da soja quando cultivado sobre cártamo, braquiária, crambe e no solo SC. No entanto, vale ressaltar que, conforme os níveis propostos por Embrapa (2006), em nenhum dos tratamentos os teores de fósforo, ou algum dos demais nutrientes da soja, foram interpretados como baixos.

\section{Conclusões}

Com exceção do cártamo, constata-se que o uso de cobertura vegetal do solo reduz o número de estipes e apotécios de S. sclerotiorum. As coberturas com braquiária, girassol e nabo forrageiro aumentam o período de tempo até a formação do apotécio, porém, somente braquiária reduz a porcentagem de apotécios formados.

A cobertura do solo com palha de girassol prejudica o desenvolvimento e o rendimento da cultura da soja.

\section{Agradecimentos}

A CAPES pela concessão da bolsa de doutorado ao primeiro autor.

\section{Referências}

ALMEIDA, A. M. R.; FERREIRA, L. P.; YORINORI, J. T.; SILVA, J. F. V.; HENNING, A. A. Doenças da soja. In: KIMATI, H.; AMORIM, L.; BERGAMIN FILHO, A.; CAMARGO, L. E. A.; REZENDE, J. A. M. Manual de fitopatologia: doenças de plantas cultivadas. São Paulo: Agronômica Ceres, 1997. v. 2, cap. 61, p. 642-664. 
ANGUS, J. F.; GARDNER, P. A.; KIRKEGAARD, J. A.; DESMARCHELIER, J. M. Biofumigation: isothiocyanates released from Brassica roots inhibit growth of the take-all fungus. Plant Soil, The Hague, v. 162, n. 1, p. 107-112, 1994.

BOLTON, M. D.; THOMMA, B. P. H. J.; NELSON, B. D. Sclerotinia sclerotiorum (Lib.) de Bary: biology and molecular traits of a cosmopolitan pathogen. Molecular Plant Pathology, Oxford, v. 7, n. 1, p. 1-16, 2006.

BORDIN, I.; NEVES, C. S. V. J.; MEDINA, C. C.; SANTOS, J. C. F.; TORRES, E.; URQUIAGA, S. Matéria seca, carbono e nitrogênio de raízes de soja e milho em plantio direto e convencional. Pesquisa Agropecuária Brasileira, Brasília, v. 43, n. 12, p. 1785-1792, 2008.

CARVALHO, M. A. C.; ATHAYDE, M. L. F.; SORATTO, R. P.; ALVES, M. C.; ARF, O. Soja em sucessão a adubos verdes no sistema de plantio direto e convencional em solo de Cerrado. Pesquisa Agropecuária Brasileira, Brasília, v. 39, n. 11, p. 1141-1148, 2004.

CASTRO, O. M.; PRADO, H.; SEVERO, A. C. R.; CARDOSO, E. J. B. N. Avaliação da atividade de microrganismos do solo em diferentes sistemas de manejo de soja. Scientia Agricola, Piracicaba, v. 50, n. 2, p. 212-219, 1993.

CLARKSON, J. P.; STAVELEY, J.; PHELPS, K.; YOUNG, C. S.; WHIPPS, J. M. Ascospore release and survival in Sclerotinia sclerotiorum. Mycological Research, Cambridge, v. 107, n. 2, p. 213-222, 2003.

CORREIA, N. M.; DURIGAN, J. C. Influência do tipo e da quantidade de resíduos vegetais associados a herbicidas residuais no desenvolvimento da cultura da soja. Bragantia, Campinas, v. 65, n. 3, p. 421-432, 2006.

CORSATO, J. M.; FORTES, A. M. T.; SANTORUM, M.; LESZCZYNSKI, R. Efeito alelopático do extrato aquoso de folhas de girassol sobre a germinação de soja e picão-preto. Semina: Ciências Agrárias, Londirna, v. 31, n. 2, p. 353-360, 2010.

CRUSCIOL, C. A. C.; COTTICA, R. L.; LIMA, E. V.; ANDREOTTI, M.; MORO, E.; MARCON, E. Persistência de palhada e liberação de nutrientes do nabo forrageiro no plantio direto. Pesquisa Agropecuária Brasileira, Brasília, v. 40, n. 2, p. 161-168, 2005.

CUNFER, B. M.; BUNTIN, G. D.; PHILLIPS, D. V. Effect of crop rotation on take-all of wheat in doublecropping systems. Plant Disease, St. Paul, v. 90, n. 9, p. 1161-1166, 2006.

DANIELSON, G. A.; NELSON, B. D.; HELMS, T. C. Effect of Sclerotinia stem rot on yield of soybean inoculated at different growth stages. Plant Disease, St. Paul, v. 88, n. 3, p. 297-300, 2004.
EMPRESA BRASILEIRA DE PESQUISA AGROPECUÁRIA - EMBRAPA. Tecnologias de produção de soja - região central do Brasil 2007. Londrina: Embrapa Soja: Embrapa Cerrados: Embrapa Agropecuária Oeste, 2006. 225 p. (Sistemas de Produção, 11).

FERRAZ, L. C. L.; CAFÉ FILHO, A. C.; NASSER, L. C. B.; AZEVEDO, J. Effects of soil moisture, organic matter and grass mulching on the carpogenic germination of sclerotia and infection of bean by Sclerotinia sclerotiorum. Plant Pathology, Chichester, v. 48, n. 1, p. 77-82, 1999

GASPARIM, E.; RICIERI, R. P.; SILVA, S. L.; DALLACORT, R.; GNOATTO, E. Temperatura no perfil do solo utilizando duas densidades de cobertura e solo nu. Acta Scientiarum. Agronomy, Maringá, v. 27, n. 1, p. 107-115, 2005.

GÖRGEN, C. A.; SILVEIRA NETO, A. N.; CARNEIRO, L. C.; RAGAGNIN, V.; LOBO JUNIOR, M. Controle do mofo-branco com palhada e Trichoderma harzianum 1306 em soja. Pesquisa Agropecuária Brasileira, Brasília, v. 44, n. 12, p. 1583-1590, 2009.

KUPIDLOWSKA, E.; GNIAZDOWSKA, A.; STEPIEN, J.; CORBINEAU, F.; VINEL, D.; SKOCZOWSKI, A.; JANECZKO, A.; BOGATEK, R. Impact of sunflower (Helianthus annuиs L.) extracts upon reserve mobilization and energy metabolism in germinating mustard (Sinapis alba L.) seeds. Journal Chemical of Ecology, New York, v. 32, n. 12, p. 2569-2583, 2006.

LOBO JUNIOR, M.; BRANDÃO, R. S.; CORREAA, C. A.; GÖRGEN, C. A.; CIVARDI, E. A.; OLIVEIRA, P. Uso de Braquiárias para o manejo de doenças causadas por patógenos habitantes do solo. Santo Antônio de Goiás: Embrapa Arroz e Feijão, 2009. 8 p. (Comunicado técnico, 183).

MALAVOLTA, E. A.; VITTI, G. C.; OLIVEIRA, S. A. Avaliação do estado nutricional das plantas: princípios e aplicações. Piracicaba, POTAFOS, 1997. 201 p.

MARCELO, A. V.; CORÁ, J. E.; FERNANDES, C.; MARTINS, M. R.; JORGE, R. F. Crop sequences in notillage system: effects on soil fertility and soybean, maize and rice yield. Revista Brasileira de Ciência do Solo, Viçosa, MG, v. 33, n. 2, p. 417-428, 2009.

NAPOLEÃO, R.; CAFÉ-FILHO, A. C.; NASSER, L. C. B.; LOPES, C. A.; SILVA, H. R. Intensidade do mofobranco do feijoeiro em plantio convencional e direto sob diferentes lâminas d'água. Fitopatologia Brasileira, Brasília, v. 30, n. 4, p. 374-379, 2005. 
NOVO, M. C. S. S.; TANAKA, R. T.; MASCARENHAS, H. A. A.; BORTOLETTO, N.; GALLO, P. B.; PEREIRA, J. C. V. N. A.; VARGAS, Á. A. T. Nitrogênio e potássio na fixação simbiótica de $\mathrm{N}_{2}$ por soja cultivada no inverno. Scientia Agricola, Piracicaba, v. 56, n. 1, p. 143156, 1999.

PAULA JÚNIOR, T. J.; VIEIRA, R. F.; ROCHA, P. R. R.; BERNARDES, A.; COSTA, E. L.; CARNEIRO, J. E. S.; VALE, F. X. R.; ZAMBOLIM, L. Intensidade do mofo branco em feijão em função de densidade de plantas, frequência de irrigação, cobertura vegetal do solo, Trichoderma spp. e fungicida. Summa Phytopathologica, Botucatu, v. 35, n. 1, p. 44-48, 2009.

PEDRAS, M. S. C.; AHIAHONU, P. W. K.; HOSSAIN, M. Detoxification of the cruciferous phytoalexin brassinin in Sclerotinia sclerotiorum requires an inducible glucosyltransferase. Phytochemistry, Oxford, v. 65 , n. 19 , p. 2685-2694, 2004.

PEREIRA, A. L.; MOREIRA, J. A. A.; KLAR, A. E. Efeito de níveis de cobertura do solo sobre o manejo da irrigação do feijoeiro (Phaseolus vulgaris L.). Irriga, Botucatu, v. 7, n. 1, p. 42-52, 2002.

RONCATTO, F.; VIECELLI, C. A. Adubação verde de girassol sobre o desenvolvimento do milho. Cultivando o Saber, Cascavel, v. 2, n. 3, p. 1-6, 2009.
SCHILLINGER, W. F; PAULITZ, T. C. Reduction of Rhizoctonia bare patch in wheat with barley rotations. Plant Disease, St. Paul, v. 90, n. 3, p. 302-306, 2006.

SILVA, R. H.; ROSOLEM, C. A. Crescimento radicular de soja em razão da sucessão de cultivos e da compactação do solo. Pesquisa Agropecuária Brasileira, Brasília, v. 37, n. 6, p. 855-860, 2002.

SODRÉ FILHO, J.; CARDOSO, A. N.; CARMONA, R.; CARVALHO, A. M. Fitomassa e cobertura do solo de culturas de sucessão ao milho na região do Cerrado. Pesquisa Agropecuária Brasileira, Brasília, v. 39, n. 4, p. 327-334, 2004.

SUN, P.; YANG, X. B. Light, temperature, and moisture effects on apothecium production of Sclerotinia sclerotiorum. Plant Disease, St. Paul, v. 84, n. 12, p. 1287-1293, 2000.

WRATHER, J. A.; ANDERSON, T. R.; ARSYAD, D. M.; GAI, J.; PLOPER, L. D.; PORTA-PUGLIA, A.; RAM, H. H.; YORINORI, J. T. Soybean disease loss estimates for the top 10 soybean producing countries in 1994. Plant Disease, St. Paul, v. 81, n. 1, p. 107-110, 1997. 
